\title{
Effect of Formulated Yeast in Suppressing the Liberation of Botrytis cinerea Conidia
}

Darryl W. M. Cook, The Horticulture and Food Research Institute of New Zealand. Private Bag 3123 Hamilton, New Zealand

\begin{abstract}
Cook, D. W. M. 2002. Effect of formulated yeast in suppressing the liberation of Botrytis cinerea conidia. Plant Dis. 86:1265-1270.

Eight yeast isolates that bound directly to Botrytis cinerea germlings were assessed for the ability to suppress spore liberation of conidia from $B$. cinerea. After the yeast cell suspension from each isolate was mixed with cellulose and dried, the product was milled into a fine powder. This yeast-cellulose formulation was applied as a dry powder to sporulating $B$. cinerea colonies on kiwifruit (Actinidia deliciosa) leaf disks, where the particles from the formulation attached to conidiophores and conidia. Some of these formulations significantly suppressed the liberation of conidia from treated colonies. Suppression of conidial liberation could provide another management tool for the biological control of sporulating $B$. cinerea with applications during late epidemic development. Using $\alpha$-cellulose prepared with Candida pulcherrima in the conditions imposed in the present study, there was an approximately $50 \%$ reduction in the number of conidia released with the treatment of the $B$. cinerea lesions. The suppression of disease through a reduction in the population of liberated conidia is discussed.
\end{abstract}

Additional keywords: adhesion, attachment, biocontrol, cellulose, Sigmacell

Spore transport is an important process in the development of disease epidemics (1). Dispersal of the pathogen Botrytis cinerea (Pers.:Fr.), can be achieved by various mechanisms (19), including airborne conidia $(13,20)$, insect-vectored conidia $(14,15)$, or splash-dispersed conidia (19). The contribution made by airborne conidia to epidemic development varies with the pathosystem under consideration $(12,20)$.

Reduction in the number of airborne conidia by suppressing $B$. cinerea sporulation has been shown to be a successful approach for management of this pathogen (27,29). Kohl et al. (23) manually removed necrotic leaves from a planting of onions, which reduced the spore load above the crop and significantly retarded epidemic development. A similar study in kiwifruit confirmed that removal of necrotic tissue to suppress spore populations resulted in a significant reduction in postharvest disease (12). A number of fungi and yeasts have been reported to reduce the sporulation of B. cinerea $(11,27)$ and some have significantly retarded epidemic development in the field or under glasshouse environments $(21,22,24)$. The use of plastic filters to

Corresponding author: D. Cook

E-mail: Cookwurms@clear.net.nz

Accepted for publication 8 July 2002.

Publication no. D-2002-0910-01R

(C) 2002 The American Phytopathological Society exclude specific wavelengths of sunlight suppressed sporulation in vitro $(10,13)$ but results were inconsistent in the glasshouse (10). Reductions of 35 to $75 \%$ in aerial spore populations were reported but these levels did not reduce disease incidence and it was concluded that the spore population within the glasshouse was not a limiting factor in epidemic development (10).

Many of the reports of suppression of sporulation and retarded epidemic development require application of the biocontrol agent (BCA) to be made early in pathogen lesion development. Although there have been some recent reports in which a BCA was applied 5 days after $B$. cinerea inoculation (28), these applications appear to be prior to pathogen sporulation. Timely antagonist application still is required in order to maximize the beneficial effects of the antagonist. Although certain phases of the pathogen, (for example, conidial germination) have been targeted for biocontrol, $B$. cinerea sporulation is a phase of the pathogen life cycle that remains relatively new for biocontrol opportunities.

B. cinerea produces conidia on determinate, highly branched conidiophores that project from the host surface (18). Spore release is regarded as passive $(1,2,18)$, although it has been proposed that a twisting motion in the conidiophore, induced by changes in relative humidity, assisted spore liberation both within a single conidiophore and by physically moving neighboring conidiophores (19). These reproductive structures exposed to the environment could present opportunities for colonization by products that could interfere with normal spore dispersal processes. The basis of such products may be found in a group of yeasts that were selected for the ability to bind to $B$. cinerea germlings $(5,8)$ and to suppress $B$. cinerea infection in vivo (8) in postharvest storage (7) and in glasshouses (4). This adhesion behavior could be harnessed and the yeasts formulated into a product with enhanced binding to $B$. cine$r e a$, thereby trapping conidia within the lesion.

In this article, the effect on conidial release and dispersal of yeasts formulated into such a product, then applied to sporulating $B$. cinerea colonies growing on kiwifruit leaf disks, is presented. A series of three experiments are described, each designed to specifically address three questions. Does the application of the yeast reduce conidial release? Is the reduction of release likely to be epidemiologically significant by comparing treatment effects with no spore release? What is the fate of those spores that are released from a treated colony?

\section{MATERIALS AND METHODS}

Inoculum preparation. Botrytis cinerea (Pers.:Fr.) isolate BC20 $(4,7,8)$ was stored in $15 \%$ glycerol at $-20^{\circ} \mathrm{C}$ and was used in all experiments in this study. Stock cultures were grown on potato dextrose agar (PDA; Difco Laboratories, Detroit) for 10 days at $18^{\circ} \mathrm{C}$, and exposed to a 12-h photoperiod from near-UV lights (Sankyo FL30 BLB, $30 \mathrm{~W}$ ) and fluorescent lights (NEC 30SSBR-HG) located $40 \mathrm{~cm}$ above the petri dishes.

Dried leaf disks (20 $\mathrm{mm}$ in diameter) from kiwifruit (Actinidia deliciosa cv. Hayward) were sterilized by gamma irradiation, then rehydrated in high humidity chambers for $16 \mathrm{~h}$ at $18^{\circ} \mathrm{C}$. The adaxial surface of each leaf disk was inoculated with dry $B$. cinerea conidia by placing the disks directly onto a sporulating stock culture. The disks were then lifted form the culture that was used as inoculum and incubated in the high-humidity chambers for 10 days. Following incubation, sporulating leaf disks were visually evaluated and those with a similar density of conidiophores were selected. Each disk was cut in half and pairs of half-disks were randomly selected to form each experimental unit which, unless otherwise stated, defined the population of conidia from 
which liberation effects were studied following the application of the yeastcellulose treatments.

The yeast isolates used in this study were isolated and described previously (8). Cells of Candida sake (Saito \& Ota) van Uden \& Buckley (isolates, 561, 532, and 662dia), C. pulcherrima (Lindner) Windisch (isolate 662dib), Trichosporon pullulans (Lindner) Diddens \& Lodder (isolate 622b), and Galactomyces geotrichum (E. E. Butler \& L. J. Peterson) Redhead \& Malloch group A (isolates 552c and 572c) were stored in $15 \%$ glycerol at $-20^{\circ} \mathrm{C}$ until required. The isolates were cultured in 100 $\mathrm{ml}$ of nutrient yeast dextrose broth (NYDB; nutrient broth at $8 \mathrm{~g} \mathrm{liter}^{-1}$ [Difco Laboratories], yeast extract at $5 \mathrm{~g} \mathrm{liter}^{-1}$ [Difco Laboratories], and D-glucose at $10 \mathrm{~g}$ liter $^{-1}$ [BDH Laboratory Supplies, Poole $\mathrm{UK}]$ ) and the $\mathrm{pH}$ was adjusted to 4.5 with $5 \mathrm{M} \mathrm{HCl}$. This broth was inoculated with $15 \mu \mathrm{l}$ of the yeast in glycerol, then incubated at $18^{\circ} \mathrm{C}$ in $250-\mathrm{ml}$ baffled conical flasks shaken at $150 \mathrm{rpm}$ for $72 \mathrm{~h}$.

The spent culture broth was removed by centrifuging the yeast culture at $766 \times g$ (Jouan M-22 centrifuge) and the yeast cells were resuspended in $30 \mathrm{ml}$ of sterile distilled water (SDW).

The efficacy of various cellulose materials as the carrier of the yeast isolates was a second experimental factor examined in this study. $\alpha$-Cellulose (Sigma C8002; Sigma-Aldrich, St. Louis), composed of cellulose particles ranging from in size from 80 to $200 \mu \mathrm{m}$, or Sigmacell (Sigma S3504, Sigma-Aldrich), composed of 20$\mu \mathrm{m}$ cellulose particles, was added to the yeast at a rate of $0.1 \mathrm{~g} \mathrm{ml}^{-1}$ of suspension.
The cellulose-yeast suspension was thoroughly shaken by hand until a homogenous slurry was formed. The slurry was then centrifuged at $766 \times g$ to remove the liquid. The cellulose-yeast paste was spread thinly over the base of a sterile glass petri dish (90 $\mathrm{mm}$ in diameter), then placed under a low vacuum at $25^{\circ} \mathrm{C}$ for $16 \mathrm{~h}$ to dry. Each cellulose-yeast preparation then was powdered using a coffee grinder (Breville Model CG2) set at maximum speed for $30 \mathrm{~s}$. Control preparations of cellulose were made by adding SDW to the $\alpha$ cellulose or to Sigmacell and processed as described above.

Application of formulated yeast to sporulating $B$. cinerea. Plastic transfer pipettes (3-ml volume; Corning Samco Corp., San Fernando, CA) were modified by removing most of the barrel and retaining the bulb plus a $1-\mathrm{cm}$-long portion of the barrel. Yeast powder was added into the bulb, then the bulb-barrel was connected to a settling chamber (6). Briefly, the settling tower was composed of an octagonal glass cylinder $60 \mathrm{~cm}$ high and $32 \mathrm{~cm}$ wide. The bulb-barrel unit was connected directly to the inlet port $(5 \mathrm{~mm}$ in diameter) which directed discharged inoculum into the settling chamber. Yeast powder was discharged into the settling chamber by puncturing a small hole into the side of the bulb and injecting a short $(<1 \mathrm{~s})$ pulse of compressed $\mathrm{CO}_{2}$ (400 kPa gauge pressure) into the bulb (6). The cellulose-yeast powder then was allowed to settle during a 4-min period onto the two randomly selected half-disks of sporulating $B$. cinerea.

Measuring the inhibition of spore release. Standard, reproducible wind speed conditions for spore liberation were created using a Tubeaxial Fan (Innovative Industrial Co, Taiwan), with a fan diameter of 73 $\mathrm{mm}$, mounted in a square tube that was 80 $\mathrm{mm}$ wide, $80 \mathrm{~mm}$ high, and $100 \mathrm{~mm}$ long (Fig. 1). A detailed wind speed profile was measured (Fig. 1) using a Thermoanemometer (Anlor Instrument Co., Shoreview, MN). The apparatus also provided a standardized position for the placement of each pair of treated, sporulating, leaf half-disks (Fig. 1) and a standard exposure time of $30 \mathrm{~s}$.

Unless otherwise stated, treatment effects of yeast application to sporulating $B$. cinerea colonies were determined by measuring the number of conidia that remained in the sporulating $B$. cinerea colony following exposure to the wind. The number of conidia that remained was quantified by first collecting conidia from the $B$. cinerea colony using a Cyclone surface sampler (Burkard Manufacturing, Rickmansworth, UK). The sampler deposited the conidia into an Eppendorf tube. The conidia were suspended in $1 \mathrm{ml}$ of mineral oil (Shell NZ Ltd., Aukland, New Zealand), then enumerated by measuring the absorbance of conidia at $400 \mathrm{~nm}$ using a spectrophotometer (Jasco V530). Conidial concentration was calculated from absorbance values using the following equation derived from fitting a linear regression (SAS 6.12) to data obtained from a dilution series of conidia suspended in mineral oil (unpublished data $): A b s_{400}=1.2 \times 10^{-7} \times$ no. conidia $0.05 ; P_{\text {(slope) }}=0.0001, P_{\text {(intercept) }}=0.12$, $P_{\text {(model) }}=0.0001, R^{2}=0.97$.

Experiment 1: Reduction of conidial release following yeast application. Each

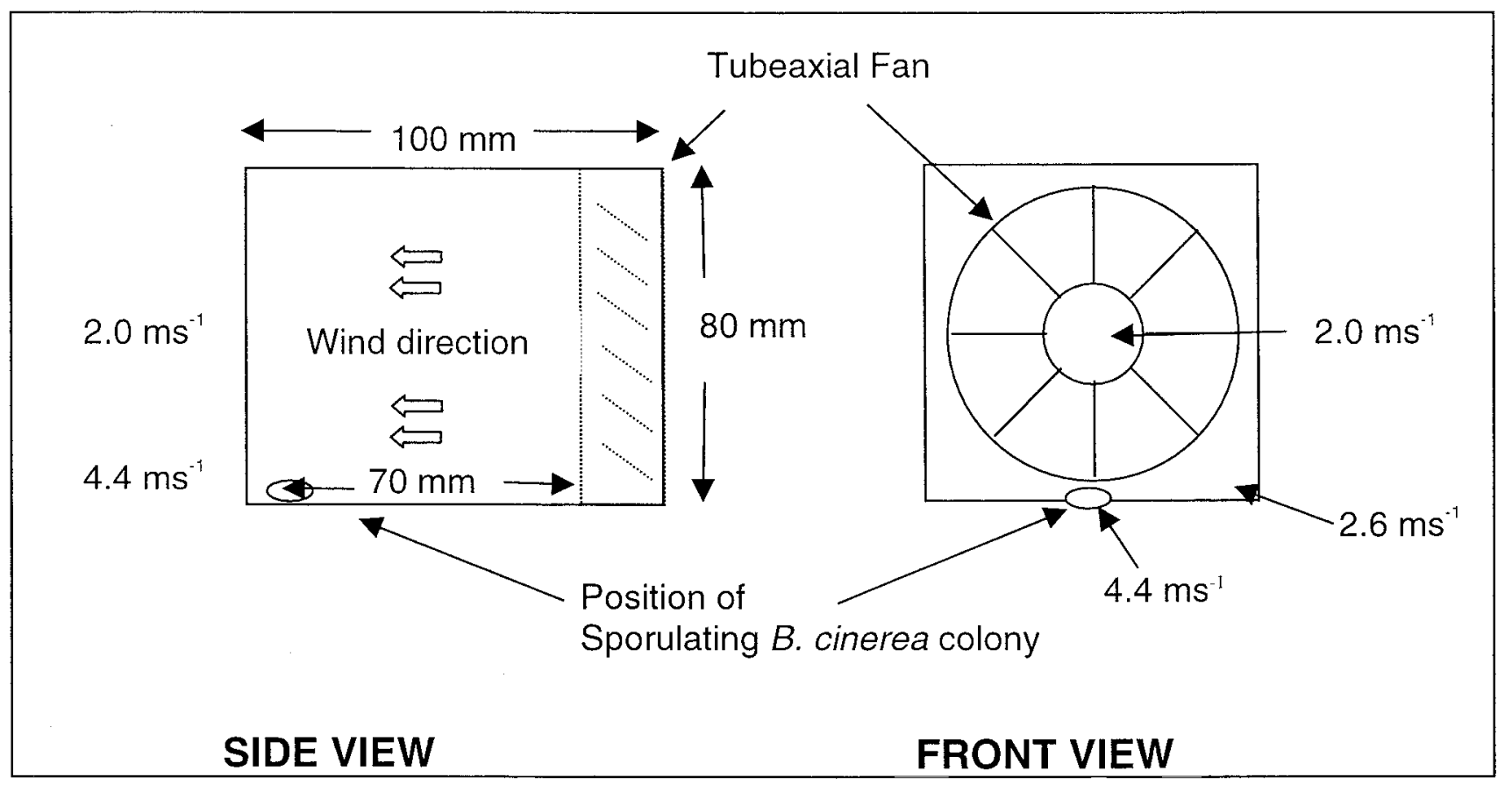

Fig. 1. The wind speed profile (meters per second) from the apparatus used to provide standard conditions for the liberation of conidia from Botrytis cinerea colonies grown on kiwifruit leaf disks. Dimensions of the apparatus and the position of the sporulating leaf samples also are indicated. 
yeast isolate was formulated in $\alpha$-cellulose, then applied at $0.2-, 0.3-$, or $0.4-\mathrm{g}$ dry powder doses to two half-disks of sporulating $B$. cinerea. Four replicate applications were made to the sporulating $B$. cinerea colonies, in which the half-disks were positioned on the settling chamber floor according to a standard design. An $\alpha$-cellulose-only control also was applied at the same three doses in four replicate applications. The experiment was carried out according to a randomized block experimental design. Following the yeast-cellulose application, all leaf half-disks were incubated for $1 \mathrm{~h}$ at $4^{\circ} \mathrm{C}$, to induce water condensation on the surface of the pathogen and encourage the adhesion of the yeast to sporulating $B$. cinerea. The treated disks were transferred to $18^{\circ} \mathrm{C}$ at ambient relative humidity for $16 \mathrm{~h}$. The effect of each isolate formulated with $\alpha$-cellulose on spore liberation was determined as described above.

The effect of yeast isolate formulated in Sigmacell on suppression of spore liberation also was examined in a repeat of the above experiment.

In both experiments, spore concentration was transformed by a $\log _{10}$ function to best fulfill the assumptions for analysis of variance (ANOVA) and analyzed using the SAS system (ver. 6.12). The effect of each yeast isolate on the number of conidia that remained in the treated $B$. cinerea colony was compared with the number of conidia that remained in $B$. cinerea colonies treated with cellulose-only using linear contrasts.

Experiment 2: Optimization of the suppression of conidial liberation. A factorial experiment was carried out to examine the following factors: yeast isolate, cellulose type, the concentration of the preparation applied, and two-way and three-way interactions among these factors.

Yeast isolates 561, 662dib, and 552c formulated in both $\alpha$-cellulose and Sigmacell products were applied to sporulating leaf segments as described above at $0.2,0.3$, and $0.4 \mathrm{~g}$. Controls composed of pairs of half-disks of sporulating $B$. cinerea treated with either $\alpha$-cellulose or Sigmacell and sporulating $B$. cinerea that was untreated and either exposed or not exposed to wind using the apparatus illustrated in Figure 1. Four replicate treatments and controls were prepared and exposed (or not exposed) to the wind. The conidia that remained in the $B$. cinerea colony were harvested using the Cyclone surface sampler. The conidia were suspended in $1 \mathrm{ml}$ of mineral oil and the absorbance measurements, taken at $400 \mathrm{~nm}$, were converted to spore concentration and $\log _{10}$ transformed for analysis by ANOVA, as described for experiment 1 . In the present experiment, each yeast treatment, the cellulose-only controls, and the untreated control exposed to the wind were compared with the no-wind, untreated control using linear contrasts. These comparisons were chosen because the objective of the suppression of conidial release was to retain to as close as possible the original population of conidia in each colony. In the present experiment, a significant biological effect of suppressing spore liberation was conferred when the treatment mean was not significantly $(P>0.05)$ from the no-wind untreated control.

Experiment 3: The fate of those spores that were released from a treated $\boldsymbol{B}$. cinerea colony. To monitor the fate of spores liberated from treated and untreated sporulating $B$. cinerea colonies, the spore cloud from sporulating leaf disks positioned in the apparatus illustrated in Figure 1 was discharged into a wind tunnel $5 \mathrm{~m}$ long, $50 \mathrm{~cm}$ high, and $70 \mathrm{~cm}$ wide. The apparatus was positioned at the head of and on the longitudinal axis of the wind tunnel. At $0.5-\mathrm{m}$ intervals along the wind tunnel, nine sampling drawers were used to locate and retrieve passive spore traps. Inoculum sources of differing sizes $(2,1,0.5$, and 0.25 sporulating disks) were placed at the head of the wind tunnel and the fan was turned on for $30 \mathrm{~s}$ to launch the pathogen conidia. The fan was turned off and this was followed by a settling time of $5 \mathrm{~min}$. The wind speed at the far end of the wind tunnel during these experiments was below the detection range of the thermoanemometer. However, experiments carried out during the construction of the wind tunnel (unpublished data), confirmed that this experimental system was sufficient to liberate most of the conidia from an untreated sporulating $B$. cinerea lesion and deposit liberated conidia within the 5-m length of the wind tunnel.

Dispersal from leaf disks treated with $0.4 \mathrm{~g}$ of the yeast 662dib (C. pullulans) formulated in $\alpha$-cellulose was compared with untreated leaf disks. Conidia released from treatments using 1 to 2 disks were trapped onto three agar-coated microscope slides at each sampling site. For the 0.5and 0.25-disk treatments, three 90-mmdiameter petri dishes with PDA amended with Triton N101 at 5,000 ppm were used at each sampling site. These plates were incubated at $18^{\circ} \mathrm{C}$ until discrete $B$. cinerea colonies were visible, then counted.

There were no spore density gradients detected along the wind tunnel; therefore, the mean spore density at each sampling site was combined to calculate an overall mean density throughout the tunnel. The means from four replicates were compared using ANOVA and Fisher's least significant difference.

\section{RESULTS}

The design of, and wind speed profile of, the apparatus to create standard conditions for spore liberation is illustrated in Figure 1. A wind speed of $4.4 \mathrm{~m} \mathrm{~s}^{-1}$ was measured where leaf disks were placed; this velocity was sufficient to remove $>90 \%$ of conidia from an untreated sporulating B. cinerea lesion (D. W. M. Cook, unpublished data).

Effect of yeast isolates on suppression of conidial liberation. Application of 0.2 $\mathrm{g}$ of $C$. sake (662dia) or G. geotrichum $(552 \mathrm{c})$ resulted in a significant increases in the number of conidia retained compared with an $\alpha$-cellulose-only control (Table 1$)$. At the 0.3-g dose, yeast isolates 561, 532, $552 \mathrm{c}$, and $572 \mathrm{c}$ conferred significant in-

Table 1. Effect of yeast isolate applied to sporulating Botrytis cinerea colonies on the suppression of conidial liberation ${ }^{\mathrm{y}}$

\begin{tabular}{|c|c|c|c|c|c|c|c|}
\hline \multirow[b]{3}{*}{ Treatment, isolate } & \multirow[b]{3}{*}{ Species } & \multicolumn{6}{|c|}{ Spore concentration (spores $\left.\times 10^{6} \mathrm{ml}^{-1}\right)^{z}$} \\
\hline & & \multicolumn{3}{|c|}{$\alpha$-cellulose } & \multicolumn{3}{|c|}{ Sigmacell } \\
\hline & & $0.2 \mathrm{~g}$ & $0.3 \mathrm{~g}$ & $0.4 \mathrm{~g}$ & $0.2 \mathrm{~g}$ & $0.3 \mathrm{~g}$ & $0.4 \mathrm{~g}$ \\
\hline Cellulose & $\ldots$ & 4.1 & 4.3 & 2.9 & 2.4 & 4.8 & 6.9 \\
\hline 532 & Candida sake & 6.0 & $6.8^{* *^{\mathrm{c}}}$ & $10.9 * * *$ & 2.2 & 7.8 & 6.0 \\
\hline 561 & C. sake & 6.9 & $8.5 * *$ & $11.6^{* * * *}$ & 5.1 & 8.1 & $13.0 *$ \\
\hline 662dia & C. sake & $9.0 *$ & 4.7 & $10.2^{* * * *}$ & 1.8 & 9.8 & $12.9 *$ \\
\hline 662dib & C. pulcherrima & 5.4 & 5.7 & $13.4^{* * * *}$ & 7.0 & 1.9 & $15.1 * *$ \\
\hline $622 \mathrm{~b}$ & Trichosporon pullulans & 4.4 & 5.5 & $9.3 * * *$ & 1.9 & 1.2 & 3.5 \\
\hline $552 \mathrm{c}$ & Galactomyces geotrichum & $10.6 * *$ & $8.9 * * *$ & $14.8^{* * *}$ & 4.4 & 2.6 & 5.3 \\
\hline $572 \mathrm{c}$ & G. geotrichum & 5.9 & $8.4 *$ & $10.5^{* * * *}$ & 5.3 & 7.7 & 4.8 \\
\hline
\end{tabular}

y Liberation = the quantity of Botrytis cinerea conidia that remained in a sporulating lesion on kiwifruit leaves after exposure to a 30 -s pulse of wind at 4.4 $\mathrm{m} \mathrm{s}^{-1}$. Means are from four replicates; $*{ }^{* *}$, and $* * *=P<0.05,0.001$, and 0.0001 , respectively, and were calculated for the comparison between the accompanying treatment and the cellulose-only control according to linear contrasts.

${ }^{\mathrm{z}}$ Spore concentration was calculated from absorbance data, $\log _{10}$ transformed, then presented in this table as back-transformed data. The yeast/cellulose product was applied to sporulating B. cinerea colonies in either $\alpha$-cellulose or Sigmacell at 0.2-, 0.3-, or 0.4-g doses of the formulated yeast per application to the settling chamber. 
creases in the number of conidia retained. At the 0.4-g dose, all of the formulated yeast isolates conferred significant increases in the number of conidia retained compared with the $\alpha$-cellulose control (Table 1).

Overall, Sigmacell-based formulations were less effective in retaining conidia on sporulating B. cinerea colonies (Table 1). Only at the highest dose of $0.4 \mathrm{~g}$, isolates of C. sake (561 and 662dia) and C. pulcherrima (662dib) conferred a significant increases in the number of conidia compared with the Sigmacell-only control.

Optimization for the suppression of spore release. The effect of various combinations of the cellulose-yeast formulation and concentration on suppression of liberation of $B$. cinerea conidia is shown in Table 2. Following exposure to wind, a significant quantity of conidia were removed from untreated sporulating colonies, from the Sigmacell or the $\alpha$-cellulose controls, and from colonies treated with the yeasts compared with the untreated nowind control (Table 2); specifically, isolates 561 and $552 \mathrm{c}$ formulated with Sigmacell and applied at the 0.2-g dose, or the yeast 561 formulated in Sigmacell and applied at $0.3 \mathrm{~g}$. For the remaining yeast treatments, there was no significant difference between a treatment mean and the nowind control, suggesting that these treatment combinations were all highly effective at suppressing conidial liberation.

The main effects in this factorial experiment (isolate, dose, and cellulose type) were all highly significant. The interaction between cellulose and isolate was statistically significant and the remaining twoway and three-way interactions were not significant (Table 2).
Fate of liberated conidia. Regardless of the initial size of the $B$. cinerea colony placed at the head of the wind tunnel, there was a significant $(P<0.05)$ suppression of conidial liberation by isolate 662dib $(C$. pulcherrima) formulated in $\alpha$-cellulose (Table 3). For each of the quantities of sporulating $B$. cinerea, approximately half of the number of conidia were liberated from treated lesions compared with untreated controls (Table 3). There were no significant differences $(P>0.05)$ in the number of conidia trapped at the various distances along the tunnel, which resulted in an even distribution of conidia throughout the length of the wind tunnel.

\section{DISCUSSION}

Conventional strategies for the biological control of B. cinerea require BCA application before or shortly after pathogen inoculum arrival. In contrast, BCA application to an already sporulating pathogen presents some unique challenges and potential opportunities for the suppression of subsequent epidemic development. In the present study, yeasts that attached to conidia and to conidiophores of $B$. cinerea and applied to sporulating pathogen colonies grown on kiwifruit leaf disks were able to significantly suppress spore liberation. The application of these yeasts to suppress conidial liberation could be used to reduce airborne inoculum and reduce epidemic development, which has been previously demonstrated following the removal of infected and sporulating plant tissue (23). Spore release has been studied and modeled for its contribution to epidemic development $(1,20)$, but studies of BCA application on spore release are lacking. Therefore, the mechanisms for the suppression of disease following BCA applications to sporulating pathogens are poorly understood.

Selection of the yeast isolate and the cellulose component in the formulation was shown here to be important for suppression of spore liberation. The $\alpha$-cellulose, which was highly effective in suppressing spore liberation at a dose of $0.4 \mathrm{~g}$ regardless of yeast isolate, was composed of large particles $(80$ to $200 \mu \mathrm{m})$. In contrast, yeasts formulated with the smaller Sigmacell particles $(20 \mu \mathrm{m})$ conferred significant suppression of spore release at the $0.4-\mathrm{g}$ dose for only three of the seven yeast isolates tested. The mechanism by which this suppression is achieved was not specifi-

Table 3. Total Botrytis cinerea conidial liberation from treated and untreated sporulating colonies of various sizes ${ }^{\mathrm{y}}$

\begin{tabular}{llc}
\hline $\begin{array}{l}\text { Inoculum } \\
\text { dose }\end{array}$ & $\begin{array}{c}\text { Treatment, } \\
\text { isolate }\end{array}$ & $\begin{array}{c}\text { Mean spore } \\
\text { density } \mathbf{~ m m}^{-2 z}\end{array}$ \\
\hline 2 Disks & Untreated & $5.62 \mathrm{a}$ \\
& 662dib & $2.77 \mathrm{~b}$ \\
1 Disk & Untreated & $3.28 \mathrm{a}$ \\
& 662dib & $1.94 \mathrm{~b}$ \\
1/2 Disk & Untreated & $0.69 \mathrm{a}$ \\
& 662dib & $0.37 \mathrm{~b}$ \\
1/4 Disk & Untreated & $0.38 \mathrm{a}$ \\
& 662dib & $0.17 \mathrm{~b}$ \\
\hline
\end{tabular}

y Colonies were treated with the yeast Candida pulcherrima (isolate 662dib) formulated in $\alpha$ cellulose.

${ }^{\mathrm{z}}$ Spore liberation was calculated from conidial densities measured at each sampling point along a $5-\mathrm{m}$ wind tunnel, then combined to calculate a single value for each treatment ( $n$ $=4$ ). The same letters following mean spore density are not significantly different at $P>$ 0.05 according to Fisher's least significant difference analysis.

Table 2. Optimization of the suppression of Botrytis cinerea conidial liberation from colonies grown on kiwifruit leaf disks ${ }^{\mathrm{v}}$

\begin{tabular}{|c|c|c|c|c|c|c|c|c|c|}
\hline \multirow[b]{3}{*}{ Factor } & \multirow[b]{3}{*}{ Treatment } & \multicolumn{7}{|c|}{ Spore concentration $\left(\text { spores } \times 10^{6} \mathrm{ml}^{-1}\right)^{\mathrm{w}}$} & \multirow[b]{3}{*}{$P$ value } \\
\hline & & \multirow[b]{2}{*}{ Control $^{y}$} & \multicolumn{2}{|c|}{$0.2 \mathrm{~g}^{\mathrm{x}}$} & \multicolumn{2}{|c|}{$0.3 \mathrm{~g}$} & \multicolumn{2}{|c|}{$0.4 \mathrm{~g}$} & \\
\hline & & & $\alpha$ & Sigma & $\alpha$ & Sigma & $\alpha$ & Sigma & \\
\hline \multicolumn{10}{|l|}{ Wind exposure } \\
\hline No-wind & Untreated & 8.2 & $\ldots$ & $\ldots$ & $\ldots$ & $\ldots$ & $\ldots$ & $\ldots$ & $\ldots$ \\
\hline Plus wind & Untreated & $0.5 * * *$ & $\ldots$ & $\ldots$ & $\ldots$ & $\ldots$ & $\ldots$ & $\ldots$ & $\ldots$ \\
\hline Plus wind & Cellulose & $\ldots$ & $1.9^{* * * *}$ & $3.4^{* *}$ & $2.6^{* *}$ & $0.9^{* *}$ & $3.2 * *$ & $1.7 * *$ & $\ldots$ \\
\hline Plus wind & 561 & $\ldots$ & 9.4 & $3.4^{*}$ & 12.2 & $3.6^{*}$ & 8.3 & 9.6 & $\ldots$ \\
\hline Plus wind & 662dib & $\ldots$ & 5.9 & 4.7 & 5.4 & 5.0 & 6.3 & 5.6 & $\ldots$ \\
\hline Plus wind & $552 \mathrm{c}$ & $\ldots$ & 5.9 & $3.2^{* *}$ & 17.6 & 5.8 & 8.8 & 5.8 & $\ldots$ \\
\hline \multicolumn{10}{|l|}{ ANOVA $^{z}$} \\
\hline Cellulose & $\ldots$ & $\ldots$ & $\ldots$ & $\ldots$ & $\ldots$ & $\ldots$ & $\ldots$ & $\ldots$ & 0.0001 \\
\hline Isolate & $\ldots$ & $\ldots$ & $\ldots$ & $\ldots$ & $\ldots$ & $\ldots$ & $\ldots$ & $\ldots$ & 0.0001 \\
\hline Dose & $\ldots$ & $\ldots$ & $\ldots$ & $\ldots$ & $\ldots$ & $\ldots$ & $\ldots$ & $\ldots$ & 0.0002 \\
\hline Cellulose $\times$ dose & $\ldots$ & $\ldots$ & $\ldots$ & $\ldots$ & $\ldots$ & $\ldots$ & $\ldots$ & $\ldots$ & 0.007 \\
\hline Isolate $\times$ dose & $\ldots$ & $\ldots$ & $\ldots$ & $\ldots$ & $\ldots$ & $\ldots$ & $\ldots$ & $\ldots$ & 0.26 \\
\hline Cellulose $\times$ isolate & $\ldots$ & $\ldots$ & $\ldots$ & $\ldots$ & $\ldots$ & $\ldots$ & $\ldots$ & $\ldots$ & 0.11 \\
\hline Cellulose $x$ isolate $x$ dose & $\ldots$ & $\ldots$ & $\ldots$ & $\ldots$ & $\ldots$ & $\ldots$ & $\ldots$ & $\ldots$ & 0.27 \\
\hline
\end{tabular}

${ }^{\mathrm{v}}$ Interaction effects of selected yeast isolates, formulation and concentration. Liberation $=$ the quantity of Botrytis cinerea conidia that remained in a sporulating lesion after exposure to a 30-s pulse of wind at $4.4 \mathrm{~m} \mathrm{~s}^{-1}$. Means are from four replicates. Treatments with an associated asterisk were statistically significantly different $(*, * *$, and $* * *=P<0.05,0.001$, and 0.0001 , respectively) from the no-wind untreated control according to linear contrasts.

${ }^{\mathrm{w}}$ Spore concentration was calculated from absorbance data, $\log _{10}$ transformed, then presented in this table as back-transformed data.

y Controls included a no-wind untreated control, or plus wind, untreated control.

${ }^{x}$ Yeast isolates Candida sake (isolate 561), Candida pulcherrima (isolate 662dib), or Galactomyces geotrichum (Isolate 552c) formulated with either $\alpha$ cellulose or Sigmacell were applied at $0.2-, 0.3-$, or $0.4-\mathrm{g}$ doses to sporulating B. cinerea colonies.

${ }^{\mathrm{z}}$ Analysis of variance. 
cally examined in this study; however, during the experiments, a number of observations were made with the use of light microscopy. Particles from the $\alpha$-cellulose appeared to become lodged on top of the conidiophores while, in contrast, particles from Sigmacell passed through the dense canopy of conidiophores (unpublished data). In addition, the conidiophores could vibrate under the influence of the wind to a greater degree in untreated controls compared with colonies treated with the $\alpha$ cellulose. The $\alpha$-cellulose resting on the conidiophores may have formed a rigid scaffold that may have resulted in considerably less conidiophore movement (unpublished data). Mechanical movement in the form of leaf shaking (17), the impact of water droplets (19), or from already released spores (9) and air turbulence (1) aid spore liberation. Conidia that are terminally borne (18) are subject to rapid release compared with those borne on lower conidiophores (17). It is possible that the $\alpha$ cellulose-based yeast formulation residing on the conidiophores could come into direct contact with many of the terminally borne conidia and interrupt their release. Nevertheless, these proposed mechanisms of the suppression of conidial liberation would require further detailed study.

The impact of suppressing spore liberation on subsequent development of $B$. cinerea epidemics will be influenced by a number of epidemic factors. In instances where inoculum is not the limiting factor in perpetuating the epidemic, reductions in airborne populations may not be effective (10). Several antagonistic fungi have significantly retarded epidemic development as a result of suppressing pathogen sporulation and reducing airborne inoculum $(21,22,24,29)$. In those studies, BCA application was made prior to sporulation and the suppressive effect was the result of prolonged and cumulative interaction with the BCA. In contrast, suppression of liberation represents a strategy with a short interaction time that would not benefit from long cumulative suppression. Wind tunnel experiments in the present study showed that approximately the same proportion of conidia are prevented from being liberated from treated colonies regardless of the initial quantity of sporulating tissue. Therefore, successful suppression of an epidemic will, among other factors, be influenced by the absolute amount of sporulating tissue at the time of BCA application. Infection studies have shown that a single $B$. cinerea conidium could induce a lesion in gerbera flowers (26) and cold-stored grape berries (3). In contrast, Coertze and Holz (3) found that single conidia did not induce lesions in fresh grape berries. Therefore, the effect of suppressing spore liberation on subsequent disease development will depend on dose thresholds for infection.

There are inconsistent reports as to the nature of $B$. cinerea conidia upon release.
Salinas et al. (26) and Coertze and Holz (3) stated that inocula were released as single spores. In contrast, Harrison and Lowe (17) stated that conidia tend to be released as clumps. In the present study, conidia were observed in the wind tunnel traps as single conidia unless they were attached to particles from the yeast powder. When inocula are released as clumps of conidia, they settle from the air currents at a higher rate (16), provided the atmosphere is not turbulent (1). Aylor (1) also proposed that clumping of conidia reduced the efficiency of pathogen dispersal during an epidemic. B. cinerea spores attached to particles from yeast powder are analogous to clumped Botrytis spores and potentially subject to enhanced rates of settling and dispersal inefficiencies. Although clumping was found periodically in the wind tunnel experiments, there was no evidence in the data to suggest there was a change in the dispersal patterns.

Suppression of conidial liberation as described in the present study may be unique in two aspects. BCA application to sporulating $B$. cinerea is a strategy seeking biocontrol opportunities during a phase in the pathogen life cycle that was previously unexplored. Suppression of spore liberation from an already sporulating lesion may provide opportunities for disease control late in an epidemic in a treatment designed to restrict further epidemic development. However, studies are required to investigate whether there would be ongoing suppression of the epidemic. Plaut and Berger (25) found there was no significant difference in the final disease severity from epidemics started from three levels of initial severity. Higher infection rates were measured in the epidemic that started with the lower initial severity. It remains unknown if patterns like those observed by Plaut and Berger (25) would be repeated following the treatment of plants with a liberation suppressant.

Second, provided that attachment competency can be maintained, there is no need to apply a living BCA to suppress conidial liberation. The BCA formulation described in the present study also could be applied as an inert product, achieving suppression of spore liberation primarily through a proposed adhesion mechanism. Whereas pre-infection and post-infection strategies require a living microorganism to be applied to the plant surface, this is not necessary in suppressing spore liberation in the manner described in the current study. Not only must the maintenance of attachment competency be determined, but careful consideration of the formulation also will be required in order to minimize any reduction in the photosynthetic rate, because the leaves will be coated in the preparation.

\section{ACKNOWLEDGMENTS}

I thank the New Zealand Foundation for Research, Science and Technology for providing a
FRST Postdoctoral Fellowship to fund this work, and R. M Beresford for critically evaluating the manuscript.

\section{LITERATURE CITED}

1. Aylor, D. E. 1990. The role of intermittent wind in the dispersal of fungal pathogens. Annu. Rev. Phytopathol. 28:73-92.

2. Chastagner, G. G., Ogawa, J. M., and Manji, B. T. 1978. Dispersal of conidia of Botrytis cinerea in tomato fields. Phytopathology 68:1172-1176.

3. Coertze, S., and Holz, G. 1999. Surface colonization, penetration, and lesion formation on grapes inoculated fresh or after cold storage with single airborne conidia of Botrytis cinerea. Plant Dis. 83:917-924.

4. Cook, D. W. M 1997. Isolation and assessment of attachment bacteria and yeasts for the biological control of Botrytis cinerea. Ph.D. thesis. Massey University, Palmerston North, New Zealand.

5. Cook, D. W. M., Dewey, F. M., Long, P. G., and Benhamou, N. 2000. The influence of simple sugars, salts and Botrytis-specific monoclonal antibodies on the binding of bacteria and yeast to germlings of Botrytis cinerea. Can J. Bot. 78:1169-1179.

6. Cook, D. W. M, Elmer, P. A. G, and Hill, R. A. Quantitative inoculation and infection of tomato stems with dry conidia from Botrytis cinerea. Australa. Plant Pathol. In press.

7. Cook, D. W. M., Long, P. G., and Ganesh, S. 1999. The combined effect of delayed application of yeast biocontrol agents and fruit curing for the inhibition of the postharvest pathogen Botrytis cinerea in kiwifruit Postharvest Biol. Technol. 16:233-243.

8. Cook, D. W. M., Long, P. G., Ganesh, S., and Cheah, L.-H. 1997. Attachment microbes antagonistic against Botrytis cinerea - biological control and scanning electron microscope studies in vivo. Ann. App. Biol. 131:503-518.

9. Davis, J. M., Eisner, A. D., Wiener, R. W., and Main, C. E. 1997. A flow visualization study of spore release using a wind tunnel-mounted laser light sheet. Plant Dis. 81:1057-1065.

10. Elad, Y. 1997. Effect of filtration of solar light on the production of conidia by field isolates of Botrytis cinerea and on several diseases of glasshouse-grown vegetables. Crop Prot. 16:635-642.

11. Elad, Y., Kohl, J., and Fokkema, N. J. 1994. Control of infection and sporulation of Botrytis cinerea on bean and tomato by saprophytic yeasts. Phytopathology 84:1193-1200.

12. Elmer, P. A. G., Whelan, H. G., Boyd-Wilson, K. S. H., and Pyke, N. B. 1997. Relationship between Botrytis cinerea inoculum in kiwifruit vines, contamination of the fruit surface at harvest and stem end rot in cool storage. Proc. Third Int. Symp. Kiwifruit. Acta Hortic. 4444:713-717.

13. Epton, H. A. S., and Richmond, D. V. 1980. Formation, structure and germination of conidia. Pages 41-83 in: The Biology of Botrytis. J. R. Coley-Smith, K. Verhoeff, and W. R. Jarvis, eds. Academic Press, London.

14. Fermaud, M., and Gaunt, R. E. 1995. Thrips obscuratus as a potential vector of Botrytis cinerea in kiwifruit. Mycol. Res. 99:267-273.

15. Fermaud, M., and Le Menn, R. 1992. Transmission of Botrytis cinerea by grape berry moth larvae. Phytopathology 82:1393-1398.

16. Ferrandino, F. J., and Aylor, D. E. 1984. Settling speed of clusters of spores. Phytopathology 74:969-972.

17. Harrison, J. G., and Lowe, R. 1987. Wind dispersal of conidia of Botrytis spp. pathogenic to Vicia faba. Plant Pathol. 36:5-15.

18. Jarvis, W. R. 1977. Botryotinia and Botrytis species: Taxonomy, physiology, and pathogenicity. Res. Branch Can. Dep. Agric. 
Monogr. No. 15, Ottawa.

19. Jarvis, W. R., 1980. Epidemiology. Pages 219-251 in: The Biology of Botrytis. J. R. Coley-Smith, K. Verhoeff, and W. R. Jarvis, eds. Academic Press, London.

20. Kerssies, A. 1993. Influence of environmental conditions on dispersal of Botrytis cinerea conidia and on post-harvest infection of gerbera flowers grown under glass. Plant Pathol. 42:754-762.

21. Kohl, J., Gerlag, M., De Haas, B. H., and Krijger, M. C. 1998. Biological control of Botrytis cinerea in cyclamen with Ulocladium atrum and Gliocladium roseum under commercial growing conditions. Phytopathology 88:568-575.

22. Kohl, J., Gerlag, M., and Grit, G. 2000. Bio- control of Botrytis cinerea by Ulocladium atrum in different production systems of cyclamen. Plant Dis. 84:569-573.

23. Kohl, J., Molhoek, W. M. L., van der Plas, C. H., and Fokkema, N. J. 1995. Suppression of sporulation of Botrytis spp. as a valid biocontrol strategy. Eur. J. Plant Pathol. 101:251259.

24. Michailides, T. J., and Elmer, P. A. G. 2000. Botrytis gray mold of kiwifruit caused by $\mathrm{Bo}$ trytis cinerea in the United States and New Zealand. Plant Dis. 84:208-223.

25. Plaut, J. L., and Berger, R. D. 1981. Infection rates in three pathosystem epidemics initiated with reduced disease severities. Phytopathology 71:917-921.

26. Salinas J., Glandorf, D. C. M., Picavet, F. D., and Verhoeff, K. 1989. Effects of temperature, relative humidity and age of conidia on the incidence of spotting on gerbera flowers caused by Botrytis cinerea. Neth. J. Plant Pathol. 95:51-64.

27. Sutton, J. C., and Peng, G. 1993. Biocontro of Botrytis cinerea in strawberry leaves. Phytopathology 83:615-621.

28. Szandala, E. S., and Backhouse, D. 2001. Suppression of sporulation of Botrytis cinerea by antagonists applied after infection. Australas. Plant Pathol. 30:165-170.

29. Zhang, P. G., Sutton J. C., and Hopkin, A. A. 1996. Inoculum concentration and time of application of Gliocladium roseum in relation to biocontrol of Botrytis cinerea in black spruce seedlings. Can. J. For. Res. 26:360-367. 